\title{
Temporal Trends in Deep Ocean Redfield Ratios
}

\author{
Markus Pahlow* and Ulf Riebesell
}

\begin{abstract}
The Redfield ratio [carbon:nitrogen:phosphorus ( $\mathrm{C}: \mathrm{N}: \mathrm{P})$ ] of particle flux to the deep ocean is a key factor in marine biogeochemical cycling. Changes in oceanic carbon sequestration have been linked to variations in the Redfield ratio on geological time scales, but this ratio generally is assumed to be constant with time in the modern ocean. However, deep-water Redfield ratios in the northern hemisphere show evidence for temporal trends over the past five decades. The North Atlantic Ocean exhibits a rising N:P ratio, which may be related to increased deposition of atmospheric nitrous oxides from anthropogenic $\mathrm{N}$ emissions. In the North Pacific Ocean, increasing C:N and C:P ratios are accompanied by rising remineralization rates, which suggests intensified export production. Stronger export of carbon in this region may be due to enhanced bioavailability of aeolian iron. These findings imply that the biological part of the marine carbon cycle currently is not in steady state.
\end{abstract}

The nutrient composition of marine surface waters affects the C:N:P elemental composition (Redfield ratio) of primary production (1). Anthropogenic emissions have the potential to significantly alter surface ocean nutrient content (2-6) and, consequently, the Redfield ratio of marine primary producers. Persistent changes in the surface ocean Redfield ratio eventually would be reflected in corresponding trends in ratios of deep-water nitrate, phosphate, and oxygen content-in this report referred to as oxidative or deep-water Redfield ratio. Whereas regional as well as vertical variations in oxidative ratios have been recognized (7), temporal differences in deep-water nutrient measurements between subsequent cruises were generally considered to be analytical errors $(8-10)$. We have reexamined such differences to test whether they represent temporal trends in deepwater apparent oxygen utilization (AOU) and oxidative ratios.

For this purpose, we analyzed open ocean deep-water nutrient and oxygen data for differences between subsequent measurements taken at approximately the same location. A large hydrographic database was compiled from the NODC SD2 and available WOCE data sets (11). We compared vertical profiles of AOU, phosphate, and nitrate concentrations measured at least 5 years apart and within $1^{\circ}$ longitude and latitude of each other (Fig. 1).

Differences in AOU and nutrient measurements can arise from changes in remineralization, circulation patterns, and preformed properties as well as measurement inaccuracy. Because our intention was to identify variations due to variable remineralization, possible chang-

Alfred Wegener Institute for Polar and Marine Research, Post Office Box 120161, D-27515 Bremerhaven, Germany.

*To whom correspondence should be addressed. Email: mpahlow@awi-bremerhaven.de es due to the other factors had to be excluded. (i) To avoid the influence of different water masses, we used data only from locations where temperature $(\mathrm{T})$ and salinity $(\mathrm{S})$ profiles matched within measurement precision over a depth range of at least $2000 \mathrm{~m}$, to which the analysis was restricted. (ii) Changes in preformed oxygen saturation or nutrient content could result from temporal variations in these constituents in areas of deep-water formation. Such variations did not seriously affect our analysis. (iii) Data marked questionable in the original data sets and from profiles showing strong apparent random variation (i.e., where differences between adjacent measurements were similar to or larger than those between surface and bottom) were excluded from the analysis. (iv) Systematic offsets between measurements from different cruises were accounted for by correcting data in the comparison range for differences in a lower (correction) depth range (Fig. 1). Instead of a single correction for each cruise as in previous studies $(8-10)$, we corrected the data at each location individually. No significant remineralization occurs in the deep North Atlantic Ocean in the correction range (12); thus, it is unlikely that differences here represent real trends. In other regions, however, remineralization is observed to a depth of more than $4000 \mathrm{~m}$ (8). In this case, alterations in export production would affect not only the comparison range but also the correction range, albeit to a much lesser degree. Hence, the results should be considered conservative.

Application of these criteria to the data set yielded 1173 stations at 447 locations, covering the years 1947 to 1994 (Table 1 and Fig. 2). For each of the four ocean basins examined, we calculated the average relative trends $(\delta)$ for AOU and the oxidative ratios AOU:N and AOU:P, which subsequently were converted to changes in $\mathrm{C}: \mathrm{N}, \mathrm{C}: \mathrm{P}$, and $\mathrm{N}: \mathrm{P}$ (13).

Our results show significant trends in the northern but not in the southern hemisphere (Fig. 3). An increase in the deep-water N:P ratio of $1.9 \pm 1.2$ per mil per year for the North Atlantic is accompanied by increases of $1.6 \pm$ 1.0 per mil per year in AOU:P and $1.7 \pm 1.2$ per mil per year in $\mathrm{C}: \mathrm{P}$, but there is no significant trend in AOU (Fig. 3A). All parameters (AOU, AOU:P, AOU:N, C:P, and C:N), with the exception of the N:P ratio, show a significant increase on the order of 1 per mil per year in the North Pacific (Fig. 3B). The large confidence intervals obtained for the South Atlantic (Fig. 3C) indicate that the data coverage in this ocean basin is insufficient for our analysis (Table 1). Despite a comparatively large database (Fig. 2) and small confidence intervals, no significant trends are observed in the South Pacific (Fig. 3D).



Fig. 1. Example profile illustrating the correction and comparison methods. Systematic offsets between measurements are estimated with data from depths where no concentration gradient exists (correction range, dark). Depth range, including the oxygen minimum and the underlying nutricline (comparison range, light), was divided into several layers. Data were interpolated to the center of each layer (horizontal lines). After correcting for the estimated systematic offset, horizontal differences in quantity $X$ give the relative temporal change between years $t_{0}$ and $t_{1}$ as

$$
\delta(X)=\left(X_{t_{1}}-X_{t_{0}}\right) /\left[X_{t_{0}}\left(t_{1}-t_{0}\right)\right]
$$

In the case of AOU (35), $X=A O U$, this serves as an estimate of the trend in nutrient regeneration rate. Deep-water nutrient content $n$ (nitrate or phosphate) consists of preformed $\left(n_{\text {pref }}\right)$ and regenerated $\left(n_{\text {reg }}\right)$ components (34):

$$
n=n_{\text {reg }}+n_{\text {pref }}
$$

where $n_{\text {reg }}=(\mathrm{AOU}) /[(\mathrm{AOU}: \mathrm{N})], \quad \mathrm{N}=\mathrm{N}$ or $\mathrm{P}$ Assuming constant $n_{\text {pref }}$ with time and setting $X=$ AOU:N, Eqs. (1) and (2) are combined to yield the relative change in AOU:N as

$$
\begin{aligned}
\delta(\mathrm{AOU}: \mathrm{N}) & =\left[(\mathrm{AOU}: \mathrm{N})_{t_{1}}\left(n_{t_{0}}-n_{t_{1}}\right)\right. \\
& \left.+\mathrm{AOU}_{t_{1}}-\mathrm{AOU}_{t_{0}}\right] /\left[\mathrm{AOU}_{t_{0}}\left(t_{1}-t_{0}\right)\right]
\end{aligned}
$$

where $\delta(\mathrm{AOU}: \mathrm{N})_{t_{1}}$ was taken as 170 and 10.625 for phosphate and nitrate, respectively $(9,36)$. The change in AOU: $\mathrm{N}$ was then converted to $\delta(\mathrm{C}: \mathrm{N})(13)$. 


\section{R E P O R T S}

Interpretation of these results requires critical evaluation of the potential magnitude of the effects of measurement inaccuracy, variations in preformed properties, and circulation changes compared with observed trends. The average temporal difference between subsequent profiles was 14 years, giving a mean absolute variation in North Atlantic N:P ratios and North Pacific AOU of more than $1 \%$. The precision of available seawater analytical methods used in data acquisition during the time covered by our analysis is better than $2 \%(10,14,15)$. Because more than 4000 data points were included in calculation of each trend, imprecision is negligible with respect to the observed trends (16). Systematic errors, which usually dominate measurement inaccuracy, have been account-

Table 1. Numbers of locations, stations, and temporal coverage for each ocean. No data from Arctic and Indian oceans were used. South Atlantic and South Pacific include corresponding sectors of the Southern Ocean.

\begin{tabular}{lcccc}
\hline Parameter & $\begin{array}{c}\text { North } \\
\text { Atlantic }\end{array}$ & $\begin{array}{c}\text { South } \\
\text { Atlantic }\end{array}$ & $\begin{array}{c}\text { North } \\
\text { Pacific }\end{array}$ & $\begin{array}{c}\text { South } \\
\text { Pacific }\end{array}$ \\
\hline Locations & 48 & 19 & 291 & 89 \\
Stations & 133 & 45 & 740 & 256 \\
Years & $1961-1991$ & $1961-1991$ & $1947-1994$ & $1957-1994$ \\
\hline
\end{tabular}

lated for this analysis corresponds to a change of $7 \mu \mathrm{mol} \mathrm{kg} \mathrm{kg}^{-1}$. Deep-water renewal takes place only in a small fraction of the North Pacific. Hence, if variations in preformed oxygen saturation had caused the observed trends, they must have been unrealistically high in the respective ocean areas. However, no such variations were observed in this data set. Furthermore, it is unlikely that natural long-term variations in deep-water preformed AOU or nutrients are responsible for the observed trends, because they do not appear in the South Pacific where the bulk of North Pacific deep water originates.

Possible interferences from circulation changes have been accounted for by excluding data from locations with significant differences in $\mathrm{T}$ or S. Effects due to the remaining small variations in these variables were estimated by deriving the relationship between AOU, S, and T for each comparison at each location in the North Pacific (17). The analysis yielded a $\delta(\mathrm{AOU})$ of $-0.2 \pm 0.25$ per mil per year - that is, considerably smaller than the observed trend of 0.7 per mil per year (18). In essence, neither measurement inaccuracy nor changes in preformed properties or circulation can account for the observed trends in oxidative ratios.

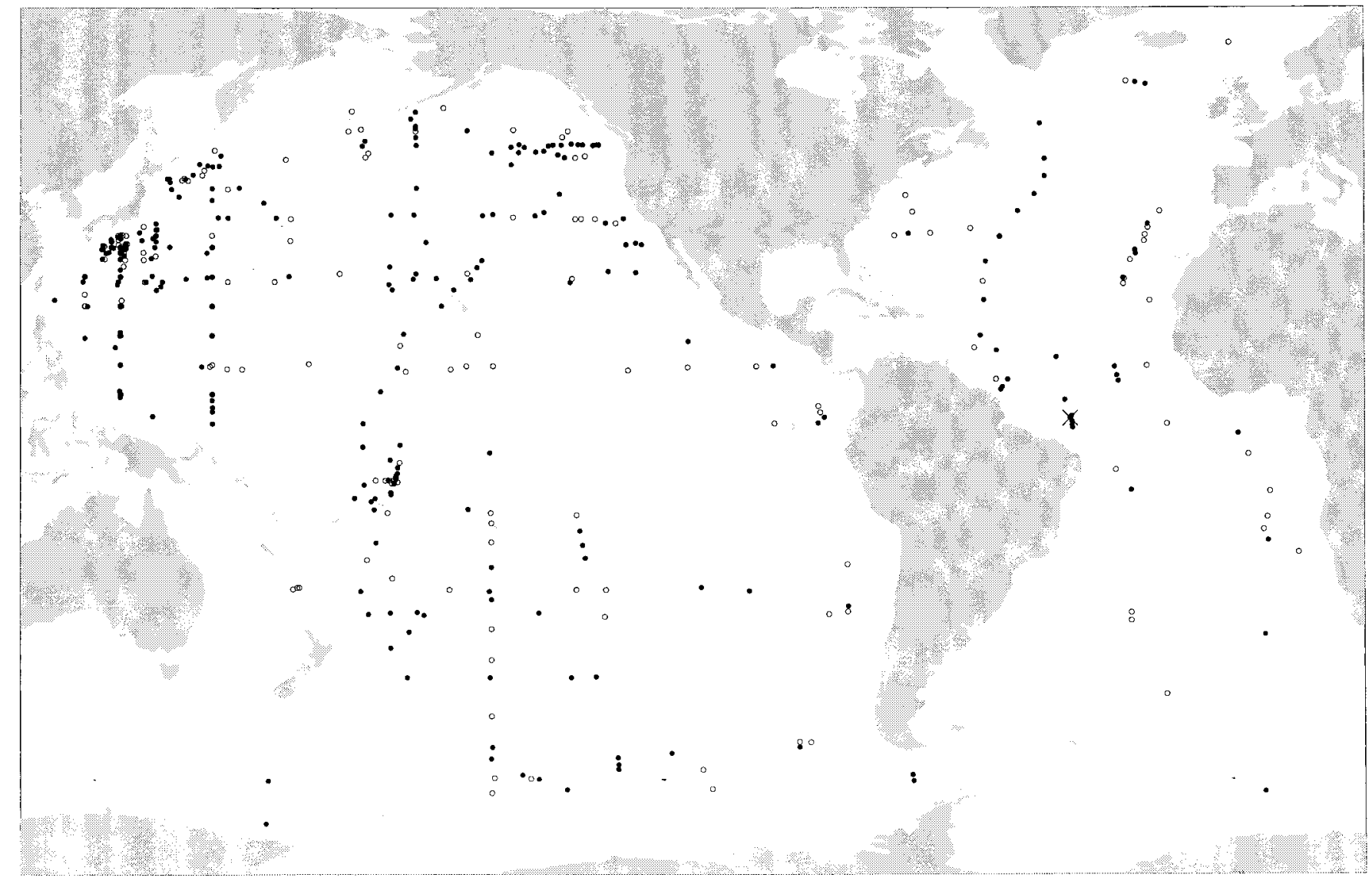

Fig. 2. Distribution of locations (circles) of stations analyzed in the Atlantic and Pacific. Closed circles, locations with rising AOU in the Pacific and N:P in the Atlantic; open circles, decreasing AOU and N:P. No data from the Arctic and Indian oceans were used. Cross in the North Atlantic marks position of the example profiles in Fig. 1. 


\section{R E P O R T S}

At this point it is not clear what may have caused the observed trends. A possible explanation for the North Atlantic results could involve, for example, a combination of accelerated deepwater formation (19) and increasing anthropogenic emissions of nitrous oxides (2). A transition from $\mathrm{N}$ to $\mathrm{P}$ limitation in parts of the North Atlantic caused by higher atmospheric $\mathrm{N}$ input (4) might explain the results for $\delta(\mathrm{AOU}: \mathrm{P})$, $\delta($ AOU:N), $\delta(C: P), \delta(C: N)$, and $\delta(N: P)$. However, this would also imply increasing AOU. Enhanced horizontal advection would decrease deep-water AOU, N, and P content and thereby possibly compensate for such an increase in AOU. However, other explanations are equally possible. For example, any process weakening export production, such as reduced nutrient transport to the surface ocean due to declining vertical mixing (20), would have an effect on deep-water AOU and nutrient content similar to that of accelerated deep-water formation.

If aeolian $\mathrm{N}$ were responsible for the observed N:P increase, the extent of atmospheric $\mathrm{N}$ input should be at least as large as the total increase in deep-water regenerated N. From this data set, we calculated average $\mathrm{AOU} \approx 120 \mathrm{~mol}$ $\mathrm{m}^{-2}$ in the depth range 500 to $2000 \mathrm{~m}$, where deep-water remineralization predominantly occurs in the North Atlantic (12). With AOU:N = $170: 16(9)$, this is equivalent to regenerated $\mathrm{N}$ at about $11 \mathrm{~mol} \mathrm{~m}^{-2}$. Hence, an increase in the deep-water regenerated $\mathrm{N}: \mathrm{P}$ ratio of $1.9 \pm 1.2$ per mil per year (Fig. 3A) would require an additional $\mathrm{N}$ supply of $21 \pm 13 \mathrm{mmol} \mathrm{m} \mathrm{m}^{-2}$ year $^{-1}$. Deposition of atmospheric $N$ over the North Atlantic has been estimated at 10 to 47 mmol m mear $^{-1}(3,21)$, most of which is anthropogenic (2). Thus, the anthropogenic increase in atmospheric $\mathrm{N}$ indeed could account for the observed N:P increase in the deep North Atlantic.

The change in export-production N:P ratio necessary to explain the $\delta(\mathrm{N}: \mathrm{P})$ found in the

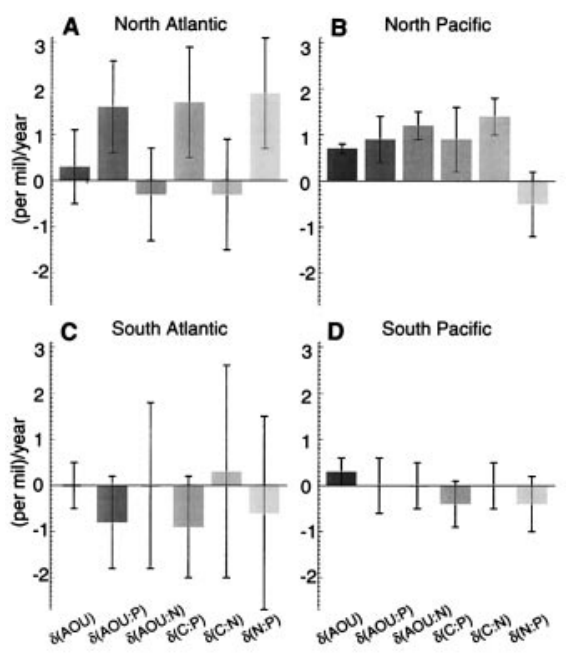

Fig. 3. Mean relative temporal trends $\delta(A O U)$, $\delta(\mathrm{AOU}: \mathrm{P}), \delta(\mathrm{AOU}: \mathrm{N}), \delta(\mathrm{C}: \mathrm{P}), \delta(\mathrm{C}: \mathrm{N})$, and $\delta(\mathrm{N}: \mathrm{P})$ in oxidative ratios with $95 \%$ confidence limits.
North Atlantic depends on the turnover time, which is the ratio of export production over the pool size of remineralized matter. We obtained a turnover time of about 40 years from exportproduction estimates $(22,23)$ and a pool size calculated from the present data set. It can be shown that this would imply a trend of about 2.5 per mil per year in export-production N:P, equivalent to a change from 15 to about 16 over the 30 years covered by our analysis.

In contrast to the North Atlantic, where primary production is mostly $\mathrm{N}$ limited (24), large parts of the Pacific, including the most productive areas, are Fe limited (25). A potential source of increasing Fe in the North Pacific is desertification in central Asia (26, 27). In addition, anthropogenically increased atmospheric $\mathrm{S}$ content $(2,4,6)$ is positively related to solubility (28), and hence bioavailability (29), of aeolian Fe (30). Fe fertilization, which stimulates export production (31, 32 ), could explain the observed increase in AOU in the North Pacific (Fig. 3B).

The additional carbon export as indicated by increasing deep-water AOU in the North Pacific was estimated from average AOU between 500 and $3000 \mathrm{~m}$ depth to about $500 \mathrm{~mol} \mathrm{~m}^{-2}$ for the present data set. With AOU:C $=1.45$ (33) and a total surface area of about $75 \times 10^{12}$ $\mathrm{m}^{2}$ (23), regenerated $\mathrm{C}$ in the North Pacific amounts to about $30010^{9}$ metric tons. An annual increase in AOU of 0.7 per mil (Fig. 3B) thus would correspond to an additional sequestration of $0.210^{9}$ metric tons of $\mathrm{C}$ per year. Because of our correction procedure (Fig. 1) and the fact that remineralization below $3000 \mathrm{~m}$ was neglected in our analysis, this value should be considered a lower limit of the actual trend.

\section{References and Notes}

1. E. Sakshaug and O. Holm-Hansen, J. Exp. Mar. Biol. Ecol. 29, 1 (1977); G.-Y. Rhee, Limnol. Oceanogr. 23, 10 (1978); R. E. Hecky and P. Kilham, Limnol. Oceanogr. 33, 796 (1988); R. E. Hecky, P. Campbell, L. L. Hendzel, Limnol. Oceanogr. 38, 709 (1993); P. H. Doering, C. A. Oviatt, B. L. Nowicki, E. G. Klos, L. W. Reed, Mar. Ecol. Prog. Ser. 124, 271 (1995).

2. J. A. Logan, J. Geophys. Res. 88, 10,785 (1983).

3. R. A. Duce, in The Role of Air-Sea Exchange in Geochemical Cycling, P. Buat-Ménard, Ed. (Reidel, Dordrecht, Netherlands, 1986), pp. 497-529.

4. K. A. Fanning, Nature 339, 460 (1989).

5. G. Zhuang, R. A. Duce, D. R. Kester, J. Geophys. Res. 95, 16207 (1990).

6. R. A. Duce et al., Global Biogeochem. Cycles 5, 193 (1991).

7. A. J. Watson and M. Whitfield, Deep-Sea Res. 32, 1023 (1985); K. A. Fanning, J. Geophys. Res. 97, 5693 (1992).

8. W. S. Broecker, T. Takahashi, T. Takahashi, J. Geophys. Res. 90, 6925 (1985).

9. L. A. Anderson and J. L. Sarmiento, Global Biogeochem. Cycles 8, 65 (1994).

10. N. Gruber and J. L. Sarmiento, Global Biogeochem. Cycles 11, 235 (1997).

11. http://nemo.ucsd.edu/nemo-front.html; http:// www.dkrz.de/ u241046/dataindex.html

12. W. S. Broecker and T. Takahashi, Deep-Sea Res. 27, 591 (1980).

13. Using an increase in $\mathrm{AOU}$ (as $\mathrm{O}_{2}$ ) by 1.2 and $2 \mathrm{~mol}$ for each mole of increase in $\mathrm{C}$ and $\mathrm{N}$, respectively (33, 34):

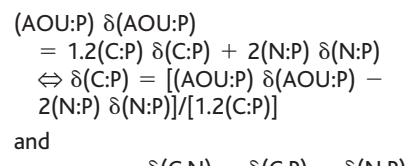

where

$\delta(C: N)=\delta(C: P)-\delta(N: P)$

$\delta(\mathrm{N}: \mathrm{P})=\{[1+\delta(\mathrm{AOU}: \mathrm{P})] /[1+\delta(\mathrm{AOU}: \mathrm{N})]\}-1$.

14. K. Grasshoff, Ed., Report on the Intercalibration Measurements at Leningrad 24-28 May 1966 and at Copenhagen September 1966 (International Council for the Exploration of the Sea, United Nations Educational, Scientific, and Cultural Organization, 1968).

15. S. W. Hager, E. L. Atlas, L. I. Gordon, A. W. Mantyla, P. K. Park, Limnol. Oceanogr. 17, 931 (1972).

16. The precision $E_{n}$ of a determination with $n$ measurements is $E_{n}=E_{1} / n^{1 / 2}$, where $E_{1}$ is the precision of a single measurement.

17. For each comparison, we collected $\mathrm{AOU}, \mathrm{S}$, and $\mathrm{T}$ data on the same density surface, within up to $5^{\circ}$ latitude and longitude of the location, and calculated the regression of $A O U$ versus $S$ and $A O U$ versus $T$. We then used these regressions to estimate the possible change in AOU due to the variations in $\mathrm{S}$ and $\mathrm{T}$.

18. Adjusting the results for this potential change would increase the observed trends. Therefore, to ensure that the results remain conservative, we did not apply this adjustment.

19. S. Bacon, Nature 394, 871 (1998).

20. A. R. Longhurst, Limnol. Oceanogr. 36, 1507 (1991).

21. A. H. Knap, T. D. Jickells, A. Pszenny, J. Galloway, Nature 320, 158 (1986).

22. J. L. Sarmiento, G. Thiele, R. M. Key, W. S. Moore, J. Geophys. Res. 95, 18303 (1990).

23. A. Longhurst, S. Sathyendranath, T. Platt, C. Caverhill, J. Plankton Res. 17, 1245 (1995).

24. C. S. Yentsch, J. Phys. Oceanogr. 12, 717 (1990).

25. F. M. M. Morel, R. J. M. Hudson, N. M. Price, Limnol. Oceanogr. 36, 1742 (1991); J. H. Martin et al., Nature 371, 123 (1994); K. H. Coale, S. E. Fitzwater, R. M. Gordon, K. S. Johnson, R. T. Barber, Nature 379, 621 (1996); M. J. Behrenfeld and Z. S. Kolber, Science 283, 840 (1999).

26. R. W. Young et al., Global Biogeochem. Cycles 5, 119 (1991).

27. Z. Zhu and T. Wang, Desert. Control Bull. 22, 27 (1993).

28. The solubility of aeolian Fe is only $10 \%$ to $50 \%$ [R. A Duce and N. W. Tindale, Limnol. Oceanogr. 36, 1715 (1991)].

29. J. H. Martin and R. M. Gordon, Deep-Sea Res. 35, 177 (1988).

30. G. Zhuang, Z. Yi, R. A. Duce, P. R. Brown, Nature 355 , 537 (1992).

31. N. M. Price, L. F. Andersen, F. M. M. Morel, Deep-Sea Res. 38, 1361 (1991).

32. K. H. Coale et al., Nature 383, 495 (1996).

33. L. A. Anderson, Deep-Sea Res. 42, 1675 (1995).

34. A. C. Redfield, B. H. Ketchum, F. A. Richards, in The Sea, M. N. Hill, Ed. (Wiley, New York, 1963), vol. 2, chap. 2.

35. Apparent oxygen utilization was determined from oxygen concentration, potential T, and $\mathrm{S}$ after Weiss [R. F. Weiss, Deep-Sea Res. 17, 721 (1970)].

36. Selecting a particular set of numbers in these calculations might seem arbitrary, because we are analyzing changes in these very ratios. However, varying $\delta(\mathrm{AOU}: \mathrm{P})_{t_{1}}$ from 130 to 200 and $\delta(\mathrm{AOU}: \mathrm{N})_{t_{1}}$ from 8 to 14 resulted in differences of $<0.13$ per mil per year in the reported trends.

37. Supported in part by the project Marine Ecosystems Regulation: Trace Metal and Carbon Dioxide Limitations (MERLIM) of the European Union within the Marine Science and Technology Programme under Contract MAS3-CT95-0005. We thank D. A. Wolf-Gladrow, A. Wischmeyer, R. Schlitzer, R. Gerdes, P. Falkowski, and T. Tyrrell for stimulating discussions on the topic and $\mathrm{S}$. Burkhardt for helpful comments on an earlier version of this manuscript. This study would not have been possible without the work of all people aboard the research vessels who collected the nutrient data and made them accessible. This is publication 1736 of the Alfred Wegener Institute for Polar and Marine Research.

16 July 1999; accepted 7 December 1999 